\title{
Hyperin Alleviates Triptolide-Induced Ovarian Granulosa Cell Injury by Regulating AKT/TSC1/mTORC1 Signaling
}

\author{
Fang You, Junyan Cao, Li Cheng, Xiaogu Liu, and Li Zeng $\mathbb{D}$ \\ The Second Clinical College, Guizhou University of Chinese Medicine, Guiyang 550000, China \\ Correspondence should be addressed to Li Zeng; zengli261@gzy.edu.cn
}

Received 26 July 2021; Revised 31 August 2021; Accepted 18 September 2021; Published 18 October 2021

Academic Editor: Talha Bin Emran

Copyright (C) 2021 Fang You et al. This is an open access article distributed under the Creative Commons Attribution License, which permits unrestricted use, distribution, and reproduction in any medium, provided the original work is properly cited.

\begin{abstract}
Premature ovarian insufficiency (POI) is characterized by the loss of ovarian function before 40 years of age and affects approximately $1 \%$ of women worldwide. Caragana sinica is a traditional Miao (a Chinese ethnic minority) medicine that improves ovarian function and follicular development. In the present study, we aimed to investigate the effect of active ingredients of C. sinica on POI and determine underlying mechanisms. Herein, the chemical composition of the C. sinica compound was analyzed using ultra-high-performance liquid chromatography, which identified hyperin (HR) as one of the main ingredients in C. sinica. Then, interaction targets of HR and POI were predicted and analyzed using network pharmacology and bioinformatics. The effect of HR on triptolide (TP)-induced granulosa cell injury was evaluated, and the underlying mechanism was explored based on bioinformatic results. A total of 100 interaction targets for POI and HR were obtained. The protein-protein interaction network of identified interaction targets emphasized the topological importance of AKT1. Kyoto Encyclopedia of Genes and Genomes (KEGG) analysis revealed that HR might regulate POI by modulating the mechanistic target of rapamycin (mTOR) signaling pathway. In addition, the KEGG graph of the mTOR signaling pathway revealed that AKT phosphorylation inhibits the TSC1/2, while TSC1/2 activation inhibits the expression of mTORC1. The fundamental experiment revealed that HR increased proliferation, progesterone receptor levels, and estradiol levels decreased by TP in KGN cells. Additionally, HR alleviated TPinduced apoptosis and G1/G1 phase arrest in KGN cells. Western blotting demonstrated that HR increased the phosphorylation of AKT and mTORC1 and decreased TSC1 expression in TP-induced KGN cells. Collectively, our findings revealed that HR alleviates TP-induced granulosa cell injury by regulating AKT/TSC1/mTORC1 signaling, providing insight into the treatment of POI.
\end{abstract}

\section{Introduction}

Premature ovarian insufficiency (POI), previously known as premature menopause or premature ovarian failure, is characterized by the loss of ovarian function before the age of 40 years and is mainly manifested as menstrual cessation, decreased androgen, and elevated gonadotropin. Meanwhile, it can lead to a series of health problems such as vascular disease, decreased bone mineral density, and decreased fertility, which seriously threatens human health [1]. And it is reported to affect about $1 \%$ of women worldwide $[2,3]$. The presently available POI treatments include stem cell treatment, assisted reproductive technology, and hormonal replacement therapy. However, these treatments are limited to clinical application, and improved therapeutic strategies are urgently needed $[4,5]$.
In recent years, medicinal plants are widely studied [6-8], some of which have anticancer activity [9], natural anthraquinone derivatives have immunomodulatory, antibacterial, and anti-inflammatory properties [10], and many studies have proved that flavonoids can act as antioxidants to prevent the degradation of antioxidants and age-related cellular components [11]. Traditional Chinese medicine has been employed for treating POI and has achieved excellent efficacy [12]. Caragana sinica is a traditional Miao (Chinese ethnic minority) medicine containing C. sinica, Hominis placenta, glossy privet fruit, and Eclipta, and it has many pharmacological activities, such as analgesia, antioxidation, anti-inflammatory, avoiding microthrombosis, regulating immune function, inhibiting tumor cell growth, and so on [13]. Previously, we reported that C. sinica compound promotes the ovulation rate, as well as follicle growth and 
development in patients with a decline in ovarian reserve [14]. C. sinica improves ovarian function and follicular development by regulating the secretion of endogenous hormones $[15,16]$. The pharmacological activity of C. sinica depends on its chemical composition. However, the active ingredients of $C$. sinica and its effect on POI have not been thoroughly investigated.

Clinical symptoms of POI primarily occur in response to dysregulated folliculogenesis and estrogen deficiency, including vulvovaginal atrophy, oligomenorrhea, amenorrhea, infertility, and vasomotor instability [10, 17]. Abnormal follicular atresia, a process characterized by follicular degeneration during growth and development, might enhance follicular depletion and result in ovarian insufficiency [10]. The decrease of ovarian reserve is related to the decrease of the number or quality of follicles and oocytes [18]. Granulosa cells refer to parietal cells wrapped on the surface of follicles, which can not only promote the formation and development of follicles, but also promote adenohormones to maintain the normal function of ovary [19]. It is reported that follicular development is accompanied by the proliferation of granulosa cells, which is regulated by the interaction between granulosa cells and oocytes [20-23]. Accumulating evidence has revealed that granulosa cell injury and apoptosis are major causes of follicular atresia [24-27]. The mechanism of affecting hormone synthesis and apoptosis of ovarian granulosa cells is complex, which is closely related to the regulation of ovarian function. It has been found that $\mathrm{PI} 3 \mathrm{~K} /$ PTEN/AKT and TSC/mTORC1 signaling pathways are key regulators of ovarian function, including quiescence, activation and survival of primordial follicles, proliferation and differentiation of granulosa cells, and meiotic maturation of oocytes $[28,29]$. Tuberous sclerosis complex (TSC) $1 / 2$ complex is considered to be the key regulator of mTOR activity. TSC1/2 plays an important role in the homeostasis and differentiation of immune cells through the negative regulation of mTOR signal pathway $[30,31]$.

In the present study, we analyzed the chemical composition of the C. sinica compound using ultra-high-performance liquid chromatography (UHPLC). Targets of hyperin (HR; one of the active ingredients of C. sinica compound) and POI were predicted and analyzed using network pharmacology and bioinformatics. Studies have proved that Tripterygium wilfordii has reproductive toxicity and can cause ovarian dysplasia and dysfunction. In this study, triptolide, one of the active ingredients of Tripterygium wilfordii, was used to induce ovarian granulosa cells injury, simulating the apoptosis or dysfunction of ovarian granulosa cells caused by ovarian dysfunction in vivo $[32,33]$. The TP-induced granulosa cells were then treated with HR to evaluate its effect on POI. Additionally, the underlying mechanism was explored based on bioinformatic results.

\section{Materials and Methods}

2.1. Detection of HR Content in C. sinica Compound. C. sinica compound granules, containing C. sinica, Hominis placenta, glossy privet fruit, and Eclipta, were supplied by Xinlvyao (Sichuan, China). UHPLC was performed to measure the active components present in $C$. sinica. The flowchart is shown in Figure 1. A $300 \mu \mathrm{l}$ aliquot of C. sinica compound was extracted with $1000 \mu \mathrm{l}$ methanol (80\%) by vortex mixing for $30 \mathrm{~s}$, with ice-water bath ultrasonic treatment performed for $5 \mathrm{~min}$. After maintaining at $-20^{\circ} \mathrm{C}$ for $1 \mathrm{~h}$ and centrifugation at $12000 \mathrm{rpm}\left(4^{\circ} \mathrm{C}\right.$ for $\left.15 \mathrm{~min}\right)$, a $5 \mu \mathrm{l}$ aliquot of the supernatant was analyzed using a Nexera UHPLC LC-30A apparatus (Shimadzu, Japan), fitted with a UPLC BEH C18 Column $(1.7 \mu \mathrm{m}, 2.1 \mathrm{~mm} \times 100 \mathrm{~mm}$; Waters Corporation). The mobile phase was composed of wateracetonitrile (gradient elution), maintained at a flow rate of $400 \mu \mathrm{l} / \mathrm{min}$. Primary and secondary mass spectra data were obtained using an AB 5600 Triple TOF mass spectrometer controlled by Analyst TF 1.7 software (AB Sciex, USA).

2.2. Network Construction and Analysis. For HR, target proteins were predicted using the TCMSP database (https:// tcmspw.com/tcmsp.php), Swiss Target Prediction database (http://www.swisstargetprediction.ch/), and Pharm Mapper database (http://www.lilab-ecust.cn/pharmmapper/). The corresponding gene symbols were obtained through alignment with UniProtID in the UniProt database (https://www. uniprot.org/). Subsequently, POI-related targets were identified using the GeneCards database (https://www. genecards.org/). The interaction targets for POI and HR were screened with $\mathrm{R}$ software using the Venn Diagram package. Cytoscape (3.6.1) was subsequently used to visualize a protein-protein interaction (PPI) network based on the obtained interaction targets. Degree, betweenness centrality, and closeness centrality were analyzed using the Network Analyzer plugin to evaluate the topological importance of the nodes in the network. Finally, the interaction targets were analyzed by bioinformatics annotation (Kyoto Encyclopedia of Genes and Genomes, KEGG, https://www. kegg.jp) using DAVID: Functional Annotation Tolls.

2.3. Cell Culture and Treatment. The human ovarian granular cell line KGN (Procell) was cultured in Dulbecco's modified Eagle's medium (DMEM)/F12 (Hyclone, USA), supplemented with $10 \%$ fetal bovine serum (FBS; Gibco, USA) and maintained at $37^{\circ} \mathrm{C}$ with $5 \% \mathrm{CO}_{2}$. On reaching 80-90\% confluency, KGN cells were treated with different concentrations of HR ( 0 (control), $0.1,1,10,50$, and $100 \mu \mathrm{g} /$ $\mathrm{ml}$; Aladdin, China) for 12, 24, and $48 \mathrm{~h}$ and TP (0 (control), $1,5,10,20,50$, and $100 \mathrm{nM}$; Aladdin, China) for $24 \mathrm{~h}$ to detect cytotoxicity. Next, cells were treated with $50 \mathrm{nM}$ TP for $24 \mathrm{~h}$ and subsequently treated with different concentrations of HR $(1,10$, and $50 \mu \mathrm{g} / \mathrm{ml})$ for $24 \mathrm{~h}$. Cell viability, apoptosis, and cell cycle were evaluated.

2.4. Cell Counting Kit-8 (CCK-8). The harvested cells were seeded into 96 -well plates at a density of $3 \times 10^{3}$ cells per well $(100 \mu \mathrm{l})$ at $37^{\circ} \mathrm{C}$ in $5 \% \mathrm{CO}_{2}$ overnight. After the different treatments, cells were cultured with an additional $10 \mu \mathrm{l}$ CCK-8 solution (Solarbio, China) for $4 \mathrm{~h}$ at $37^{\circ} \mathrm{C}$. Finally, the absorbance of each well was measured at $450 \mathrm{~nm}$ using a microplate reader (Allsheng, China). 


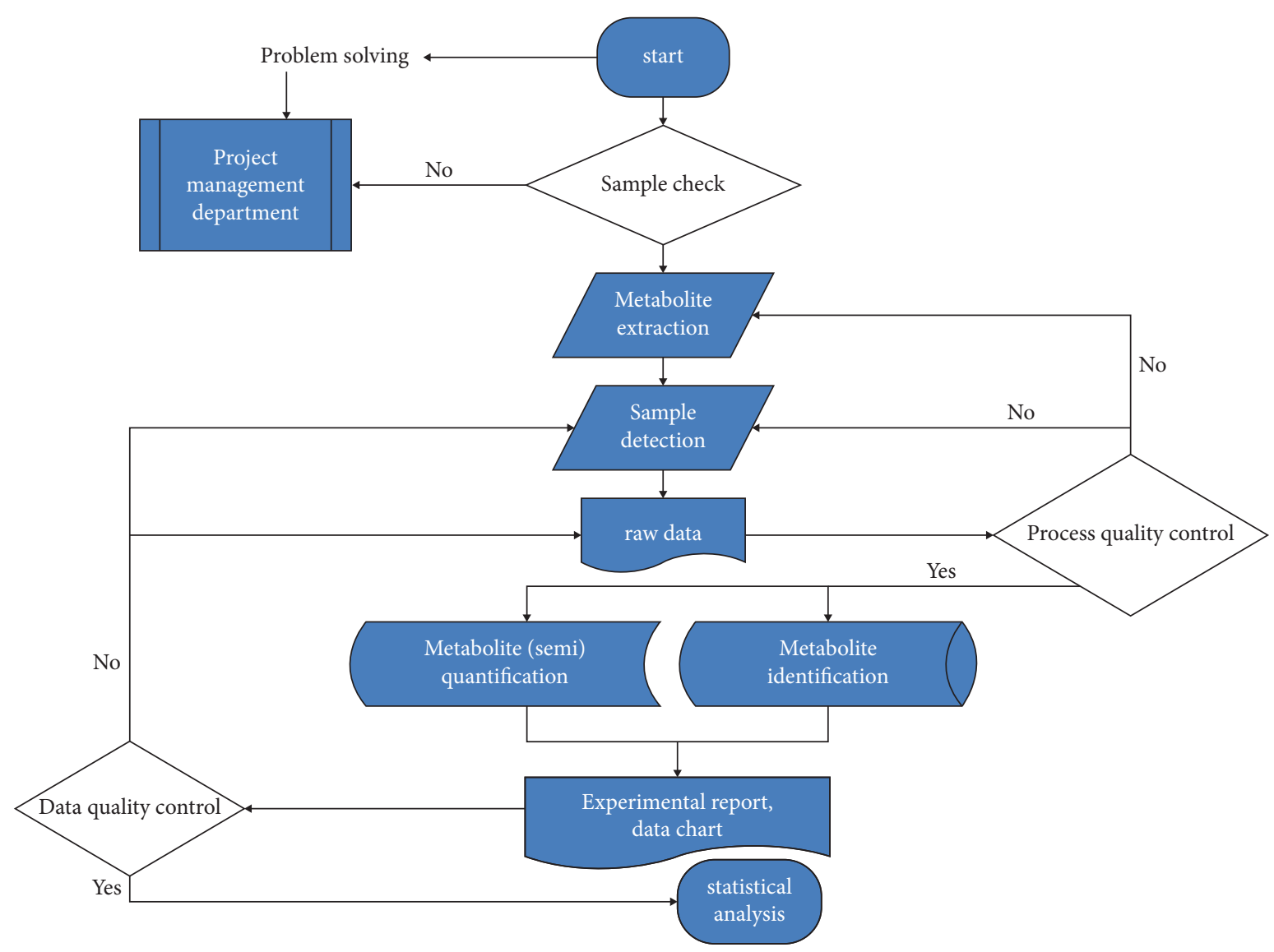

FIGURE 1: Extraction process of HR.

2.5. Flow Cytometry Assay. Flow cytometry was used to detect apoptosis and the cell cycle. For the apoptosis assay, the Annexin V-fluorescein isothiocyanate (FITC)/propidium iodide (PI) Apoptosis Detection Kit (BD, China) was used. In detail, $1 \times 10^{6}$ resuspended cells were harvested from each group and then centrifuged for $5 \mathrm{~min}$ at $400 \times g$ and $4^{\circ} \mathrm{C}$ (repeated twice). The cells were then resuspended in $200 \mu \mathrm{l}$ phosphate-buffered saline (PBS) and stained for 30 min with $10 \mu \mathrm{l}$ Annexin V-FITC and $10 \mu \mathrm{l} \mathrm{PI}$ at $4^{\circ} \mathrm{C}$ in the dark. Following the addition of $300 \mu \mathrm{l} \mathrm{PBS}$, the cells were subjected to flow cytometry (ACEA Biosciences, USA). For the cell cycle assay, $1 \times 10^{7}$ resuspended cells were harvested from each group, centrifuged at $400 \times g$ for $5 \mathrm{~min}$ at $4^{\circ} \mathrm{C}$, and resuspended in $300 \mu \mathrm{l}$ PBS. The cells were then fixed for $24 \mathrm{~h}$ in an additional $700 \mu \mathrm{l}$ absolute ethyl alcohol at $-20^{\circ} \mathrm{C}$ and centrifuged at $700 \times g$ for $5 \mathrm{~min}$ at $4^{\circ} \mathrm{C}$. Subsequently, the cells were resuspended in $100 \mu \mathrm{l}$ of $1 \mathrm{mg} / \mathrm{ml}$ RNase A solution (BD, China) and maintained at $37^{\circ} \mathrm{C}$ for $300 \mathrm{~min}$. Thereafter, $400 \mu \mathrm{l}$ and $50 \mu \mathrm{g} / \mathrm{ml}$ of PI were added and cultured at $4^{\circ} \mathrm{C}$ for $10 \mathrm{~min}$ in the dark. Finally, cells were subjected to flow cytometry (ACEA Biosciences, USA). Finally, ImageJ was used to analyze the apoptosis and cell cycle of each group.

2.6. Enzyme-Linked Immunosorbent Assay (ELISA). According to the antigen or antibody, it binds to the surface of a solid-phase carrier and maintains its immune activity. Connect the antigen or antibody with an enzyme to form an enzyme labeled antigen or antibody, which retains both its immune activity and the activity of the enzyme. During the determination, the tested sample (determining the antibody or antigen) and the enzyme labeled antigen or antibody react with the antigen or antibody on the surface of the solid carrier according to different steps. The antigen antibody complex formed on the solid-phase carrier is separated from other substances by washing. Finally, the amount of enzyme combined on the solid-phase carrier is in proportion to the amount of tested substances in the sample. After adding the substrate of enzyme reaction, the substrate is catalyzed by enzyme to become colored products. The amount of products is directly related to the amount of tested substances in the sample, so it can be analyzed qualitatively or quantitatively according to the depth of color reaction. Levels of progesterone receptor (HM10675) and estradiol (HM10669) were determined by ELISA kit (Bioswamp, China). The measurement steps are carried out in strict accordance with the instructions.

2.7. Western Blotting. Whole proteins were extracted from KGN cells using radioimmunoprecipitation assay lysis buffer (Solarbio), and the protein concentration was quantified using a bicinchoninic acid assay kit (Solarbio). In brief, $20 \mu \mathrm{g}$ of proteins in each group was separated by 


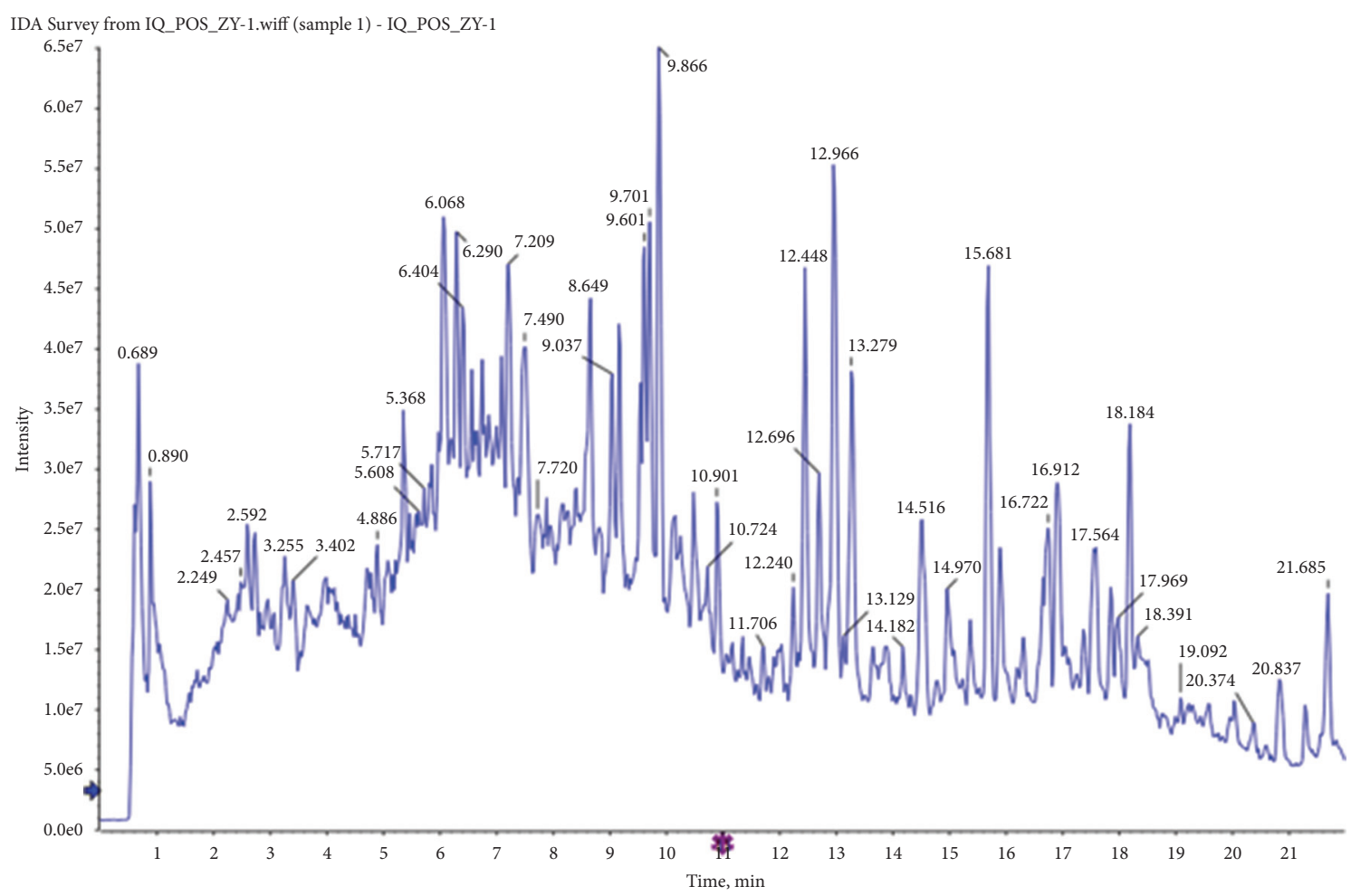

(a)

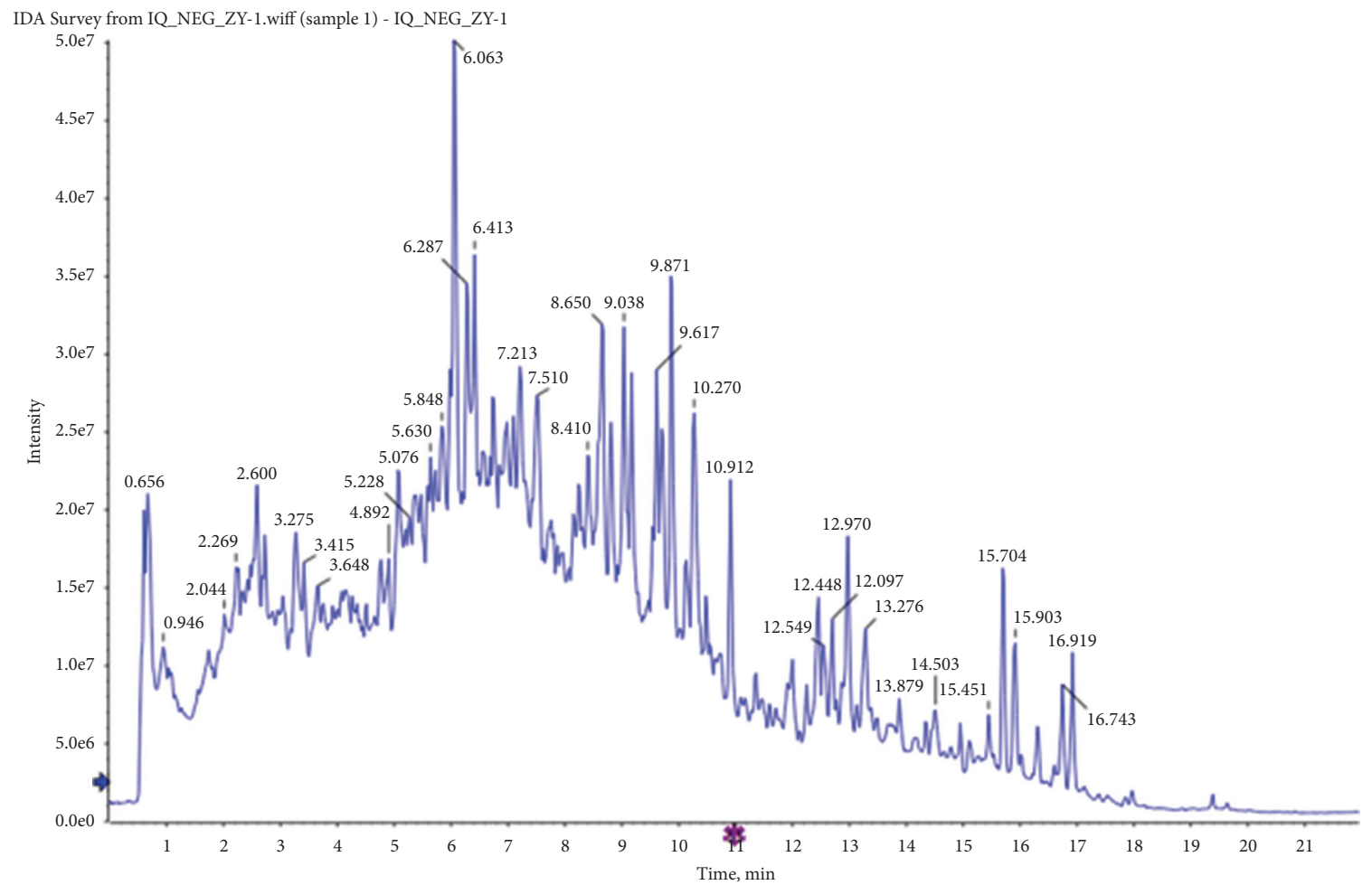

(b)

FIgURE 2: Total ion flow diagram of broom compound in positive (a) and negative (b) ion modes. 
TABLe 1: The main active constituents of Plantagenet compound detection using UHPLC-QTOF-MS.

\begin{tabular}{|c|c|c|c|}
\hline Compound name & Molecular formula & CAS number & $m / z$ \\
\hline Specnuezhenide & $\mathrm{C}_{31} \mathrm{H}_{42} \mathrm{O}_{17}$ & $39011-92-2$ & 685.2334 \\
\hline Oleamide & $\mathrm{C}_{18} \mathrm{H}_{35} \mathrm{NO}$ & $301-02-0$ & 282.2789 \\
\hline Hyperin & $\mathrm{C}_{21} \mathrm{H}_{20} \mathrm{O}_{12}$ & $482-36-0$ & 463.0874 \\
\hline 4-Caffeoylquinic acid & $\mathrm{C}_{16} \mathrm{H}_{18} \mathrm{O}_{9}$ & $905-99-7$ & 353.0872 \\
\hline Eclalbasaponin I & $\mathrm{C}_{42} \mathrm{H}_{68} \mathrm{O}_{14}$ & 158511-59-2 & 841.458 \\
\hline 5-Caffeoylquinic acid & $\mathrm{C}_{16} \mathrm{H}_{18} \mathrm{O}_{9}$ & $906-33-2$ & 353.087 \\
\hline 3,4-Dicaffeoylquinic acid & $\mathrm{C}_{25} \mathrm{H}_{24} \mathrm{O}_{12}$ & $14534-61-3$ & 515.1183 \\
\hline Astragalin & $\mathrm{C}_{21} \mathrm{H}_{20} \mathrm{O}_{11}$ & $480-10-4$ & 447.0924 \\
\hline Melezitose & $\mathrm{C}_{18} \mathrm{H}_{32} \mathrm{O}_{16}$ & $10030-67-8$ & 527.1566 \\
\hline 3,5-Dicaffeoylquinic acid & $\mathrm{C}_{25} \mathrm{H}_{24} \mathrm{O}_{12}$ & $2450-53-5$ & 515.1182 \\
\hline Lanosterol & $\mathrm{C}_{30} \mathrm{H}_{52} \mathrm{O}$ & $79-62-9$ & 427.3924 \\
\hline Luteolin 7-glucoside & $\mathrm{C}_{21} \mathrm{H}_{20} \mathrm{O}_{11}$ & $5373-11-5$ & 447.0924 \\
\hline Acteoside & $\mathrm{C}_{29} \mathrm{H}_{36} \mathrm{O}_{15}$ & $\begin{array}{c}61276-17-3 \\
(22323-52-0)\end{array}$ & 623.1975 \\
\hline Kaempferol & $\mathrm{C}_{15} \mathrm{H}_{10} \mathrm{O}_{6}$ & $520-18-3$ & 287.0553 \\
\hline Luteolin & $\mathrm{C}_{15} \mathrm{H}_{10} \mathrm{O}_{6}$ & $491-70-3$ & 285.0404 \\
\hline Beta-amyrin & $\mathrm{C}_{30} \mathrm{H}_{50} \mathrm{O}$ & $559-70-6$ & 426.72 \\
\hline Datiscetin & $\mathrm{C}_{15} \mathrm{H}_{10} \mathrm{O}_{6}$ & $480-15-9$ & 287.0549 \\
\hline Stevioside & $\mathrm{C}_{20} \mathrm{H}_{30} \mathrm{O}_{3}$ & $471-80-7$ & 318.45 \\
\hline Myristoleic acid & $\mathrm{C}_{14} \mathrm{H}_{26} \mathrm{O}_{2}$ & $544-64-9$ & 226.35 \\
\hline Rebaudioside A & $\mathrm{C}_{44} \mathrm{H}_{70} \mathrm{O}_{23}$ & $58543-16-1$ & 965.4233 \\
\hline Tiliroside & $\mathrm{C}_{30} \mathrm{H}_{26} \mathrm{O}_{13}$ & $20316-62-5$ & 593.1294 \\
\hline Ursolic acid & $\mathrm{C}_{30} \mathrm{H}_{48} \mathrm{O}_{3}$ & 77-52-1 & 456.71 \\
\hline
\end{tabular}

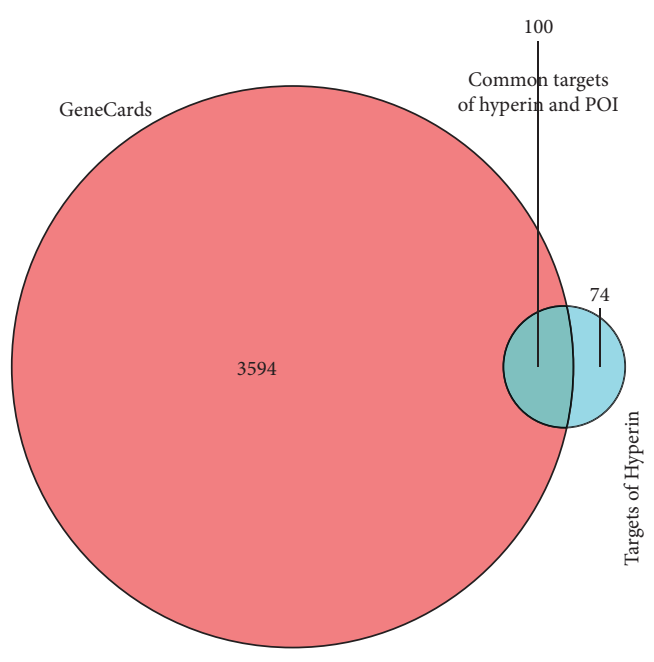

(a)

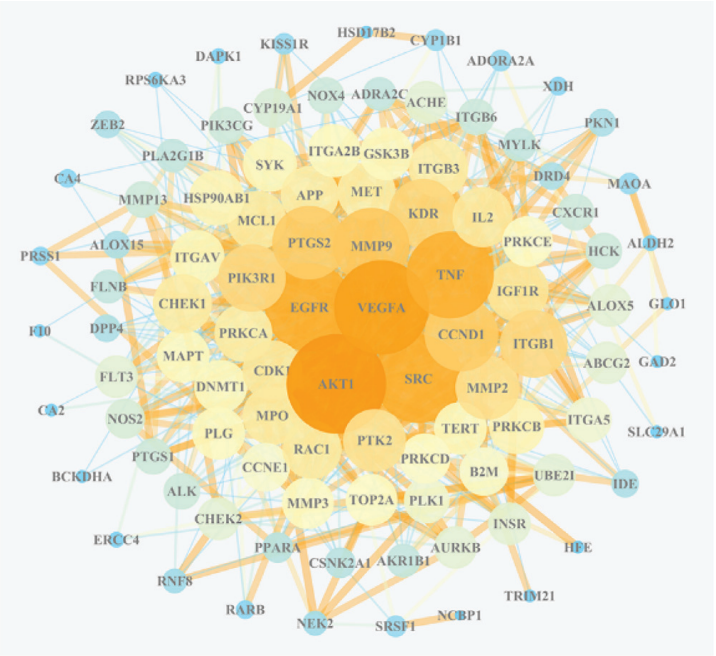

(b)

Figure 3: (a) Overlap of HR predicted targets and the POI-related targets. (b) The protein-protein interaction network of the predicted interaction targets of HR and POI. HR, hyperin; POI, premature ovarian insufficiency.

$12 \%$ sodium dodecyl sulfate-polyacrylamide gel electrophoresis and transferred onto polyvinylidene fluoride membranes (Millipore, USA). The membranes were then blocked with 5\% skim milk and cultured for $1 \mathrm{~h}$ with primary antibodies against TSC1 (Bioswamp, China), mTORC1 (Bioswamp, China), and phosphorylated (p)mTORC1 (Abcam. USA), AKT (Bioswamp, China), p-AKT (Cell Signaling Technology, USA), and GAPDH (housekeeping control, Bioswamp, China), followed by $1 \mathrm{~h}$ of incubation with goat anti-rabbit IgG secondary antibody (Bioswamp, China).
2.8. Statistical Analysis. SPSS 23.0 software was used for one-way ANOVA. Data are presented as means \pm standard deviation (SD). Differences among groups were analyzed using one-way analysis of variance followed by Tukey's test. Statistical significance was set at $p<0.05$.

\section{Results}

3.1. HR Was the Main Ingredient Detected in C. sinica Compound and Regulated POI by Modulating the AKT/TSC1/ mTORC1 Signaling Pathway. The principal components of 


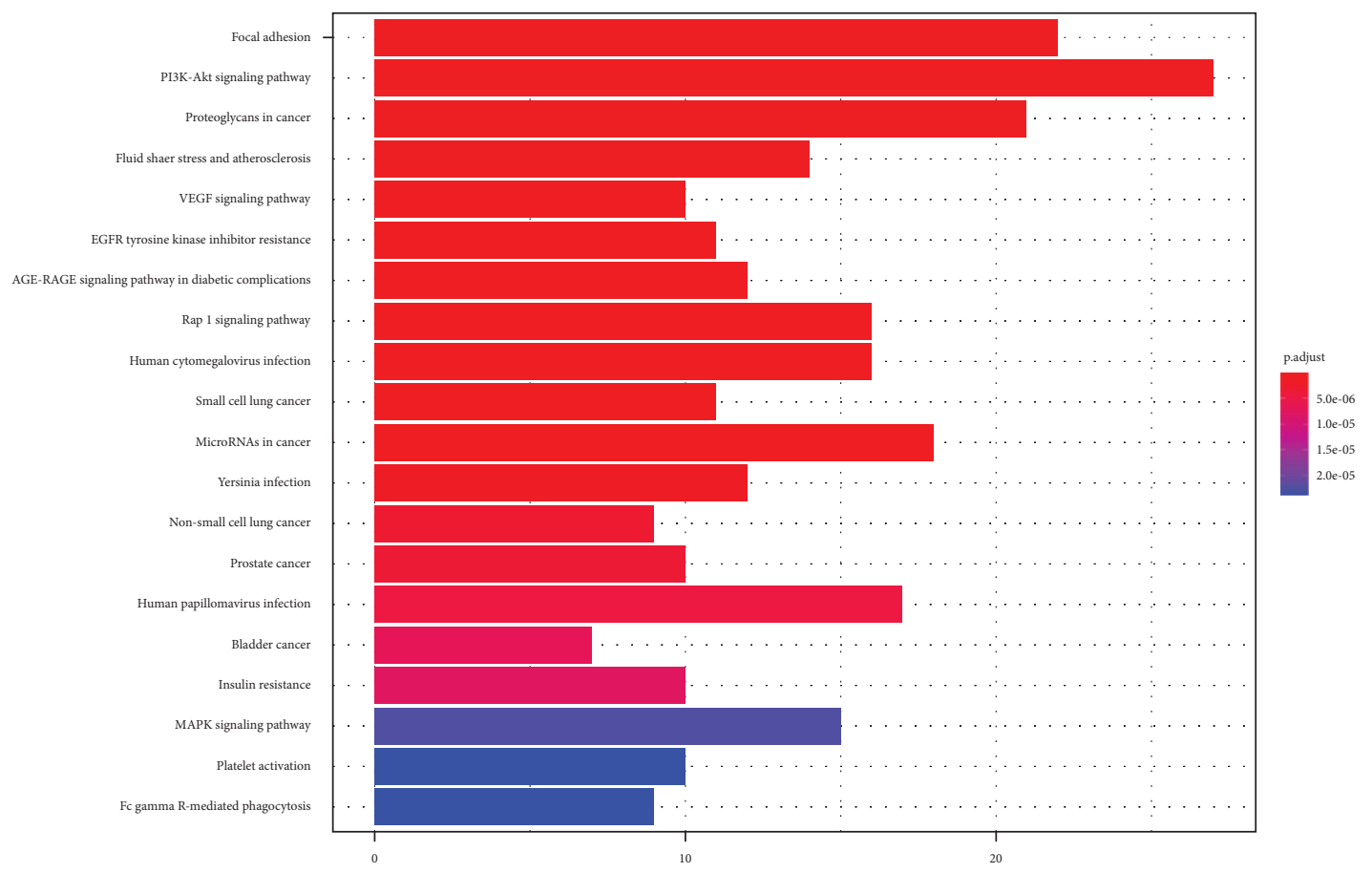

(a)

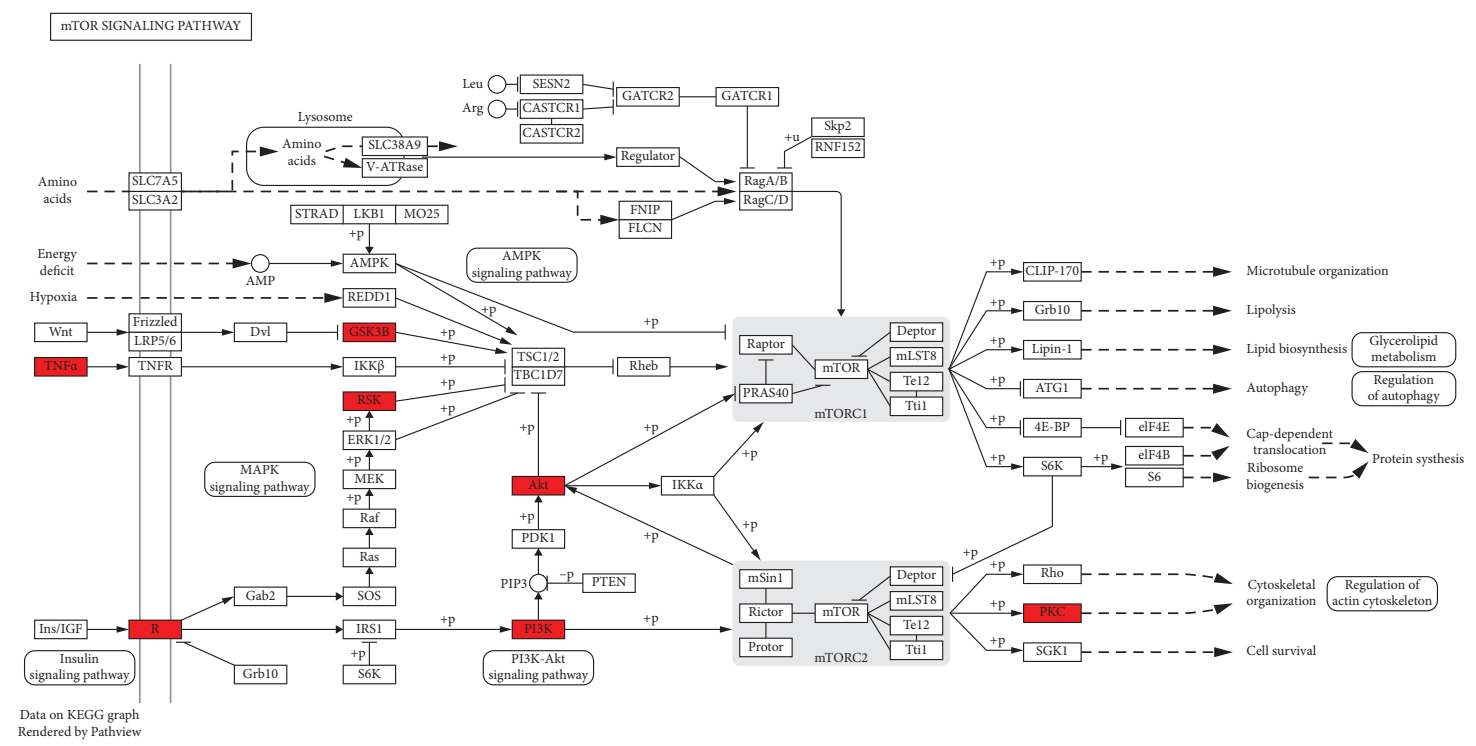

(b)

FIgure 4: (a) Top 20 enriched KEGG pathways for the predicted interaction targets of HR and POI. (b) The KEGG graph of the mTOR signaling pathway (proteins in the red frame are interaction targets of POI and HR in the mTOR signaling pathway). KEGG, Kyoto Encyclopedia of Genes and Genomes; HR, hyperin; POI, premature ovarian insufficiency; mTOR, mechanistic target of rapamycin.

compound Canary flower were analyzed by HPLC-MS. Figure 2 shows the total ion flow diagram of broom compound in positive and negative ion modes. The main active ingredients identified in the $C$. sinica compound are shown in Table 1, including HR. Overall, 174 target proteins were predicted for HR using the TCMSP database, Swiss Target Prediction database, and Pharm Mapper database predicted (Supplementary 1). A total of 3694 targets related to POI were predicted using the GeneCards database (Supplementary 2). Accordingly, 100 interaction targets for POI and HR were obtained, as shown in the Venn diagram (Figure 3(a)), and the details are shown in Supplementary 3. The PPI of the interaction targets highlighted the topological importance of AKT1, as demonstrated by the maximum degree value, betweenness centrality, and closeness centrality (Figure 3(b) and Supplementary 4). To better understand the biological effects of HR, KEGG pathway enrichment was analyzed based on predicted targets. The enrichment plots of the top 20 KEGG pathways are shown in Figure 4(a), containing the PI3K-AKT signaling pathway; the details of predicted pathways are listed in Supplementary 5, 

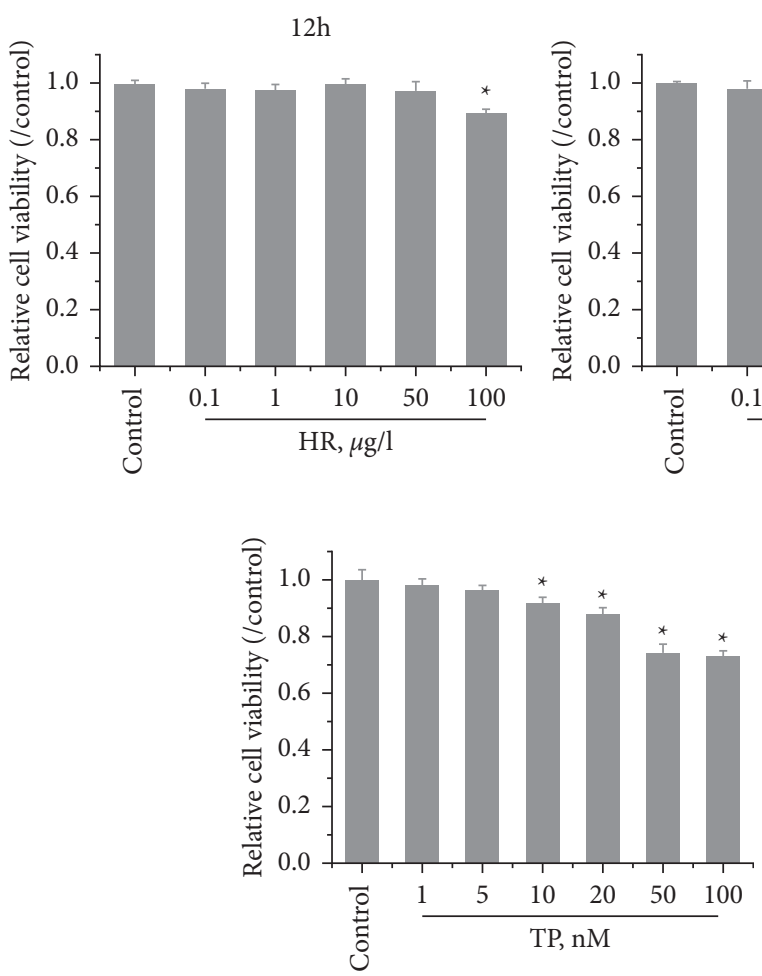

(b)
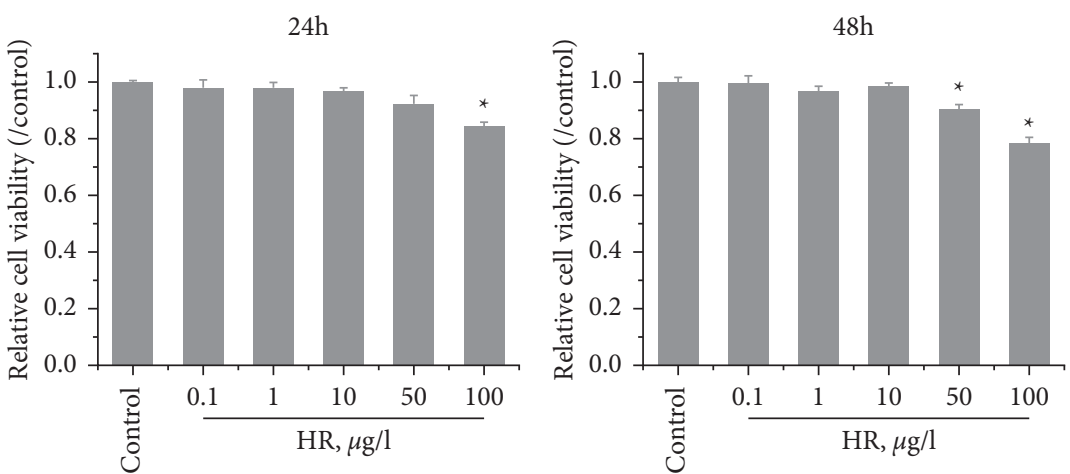

(a)

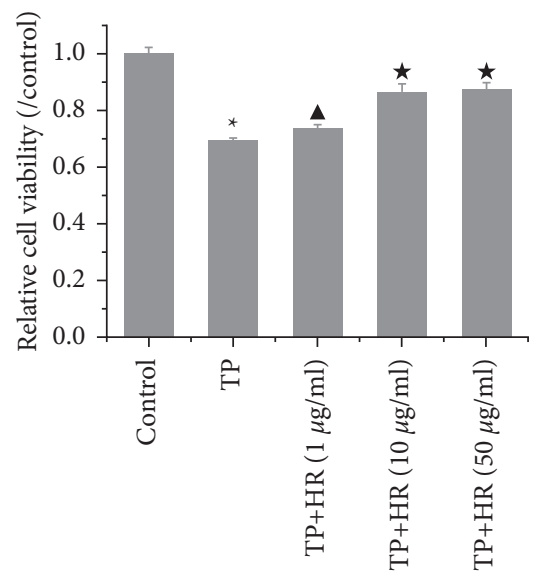

(c)

FIGURE 5: CCK-8 was performed to detect the viability of KGN cells treated with (a) HR or (b) TP alone, or (c) their combination. Data represent as mean \pm standard deviation (SD), $n=3 .{ }^{*} p<0.05 v s$. control group, ${ }^{\star} p<0.05 v s$. TP group, and ${ }^{\star} p<0.05 v s$. TP $+\mathrm{HR}(1 \mu \mathrm{g} / \mathrm{ml})$ group. HR, hyperin; TP, triptolide.

containing the mechanistic target of rapamycin (mTOR) signaling pathway (Figure 4(b)). As shown in Figure 2(b), the proteins in the red frame were the interaction targets of POI and $\mathrm{HR}$ in the mTOR signaling pathway, containing proteins such as GSK3B, PI3K, and AKT. The KEGG graph for the mTOR signaling pathway showed that AKT phosphorylation inhibits the activation of TSC1/2, while TSC1/2 activation inhibits mTORC1 expression (Figure 4(b)).

3.2. HR Promoted KGN Cell Proliferation Reduced by TP. To investigate the effect of HR on TP-induced injury in KGN cells, we first evaluated the effect of HR on normal KGN cells. The CCK- 8 assay showed that, at a low concentration (no more than $50 \mu \mathrm{g} / \mathrm{l}$ ), HR presented no cytotoxicity toward KGN cells after treatment for 12 and 24 h. However, an HR concentration exceeding $50 \mu \mathrm{g} / \mathrm{l}$ revealed cytotoxicity after treatment for $48 \mathrm{~h}$ (Figure 5(a)). Thus, 1, 10, and $50 \mu \mathrm{g} / \mathrm{l}$ of HR treatment for $24 \mathrm{~h}$ were selected for subsequent experiments. Next, to assess the cytotoxicity of TP on KGN cells, KGN cells were treated with different TP concentrations. The results demonstrated that a TP concentration of more than $10 \mathrm{nM}$ was cytotoxic. Compared with control KGN cells, the cell viability of cells treated with 10 or $20 \mathrm{nM}$ TP presented a statistical difference; the cell viability remained high (Figure 5(b)). Thus, $50 \mathrm{nM}$ TP was selected for subsequent experiments. Then, the KGN cells were treated with $50 \mathrm{nM}$ TP combined with 1,10 , and $50 \mu \mathrm{g} / \mathrm{l}$ of HR. The CCK-8 assay revealed that TP decreased the viability of KGN cells; HR increased viability in a dose-dependent manner (Figure 5(c)).

3.3. HR Alleviated Apoptosis and G1/G1 Phase Arrest Induced by TP in KGN Cells. Flow cytometry revealed that TP promoted apoptosis (Figure 6(a)) and induced G1/G1 phase arrest (Figure 6(b)) in KGN cells; HR alleviated these TPinduced effects in a dose-dependent manner.

3.4. HR Increased Levels of Progesterone Receptor and Estradiol Decreased by TP in KGN Cells. Based on ELISA findings, TP treatment decreased the levels of progesterone receptors (Figure 7(a)) and estradiol (Figure 7(b)) in KGN cells, which were increased by HR in a dose-dependent manner.

3.5. HR Increased p-AKT and p-mTORC1 Activation and Decreased TSC1 Expression in TP-Induced KGN Cells. Western blotting revealed that TP treatment inhibited the phosphorylation of AKT and mTORC1, which increased the 

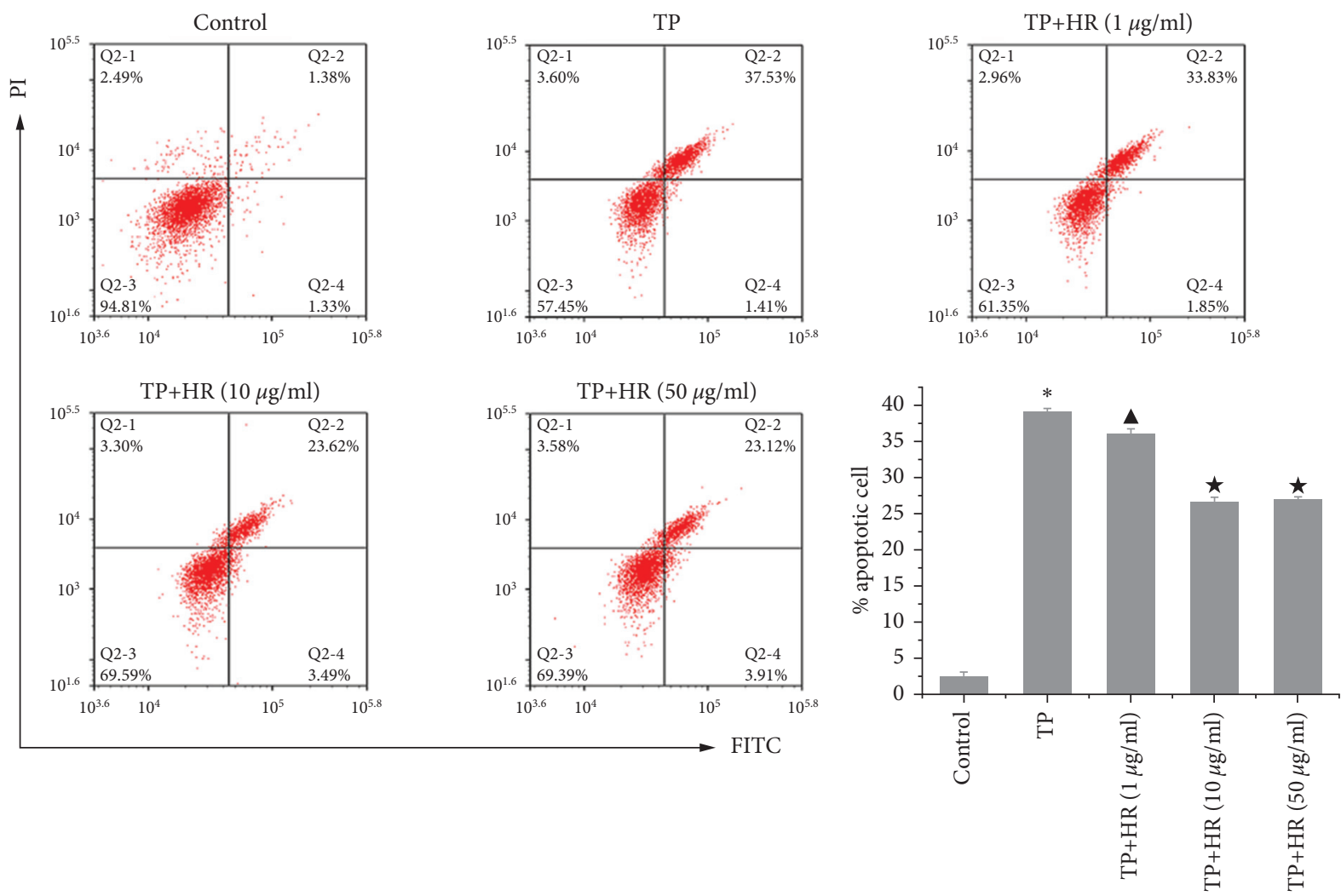

(a)

Figure 6: Continued. 

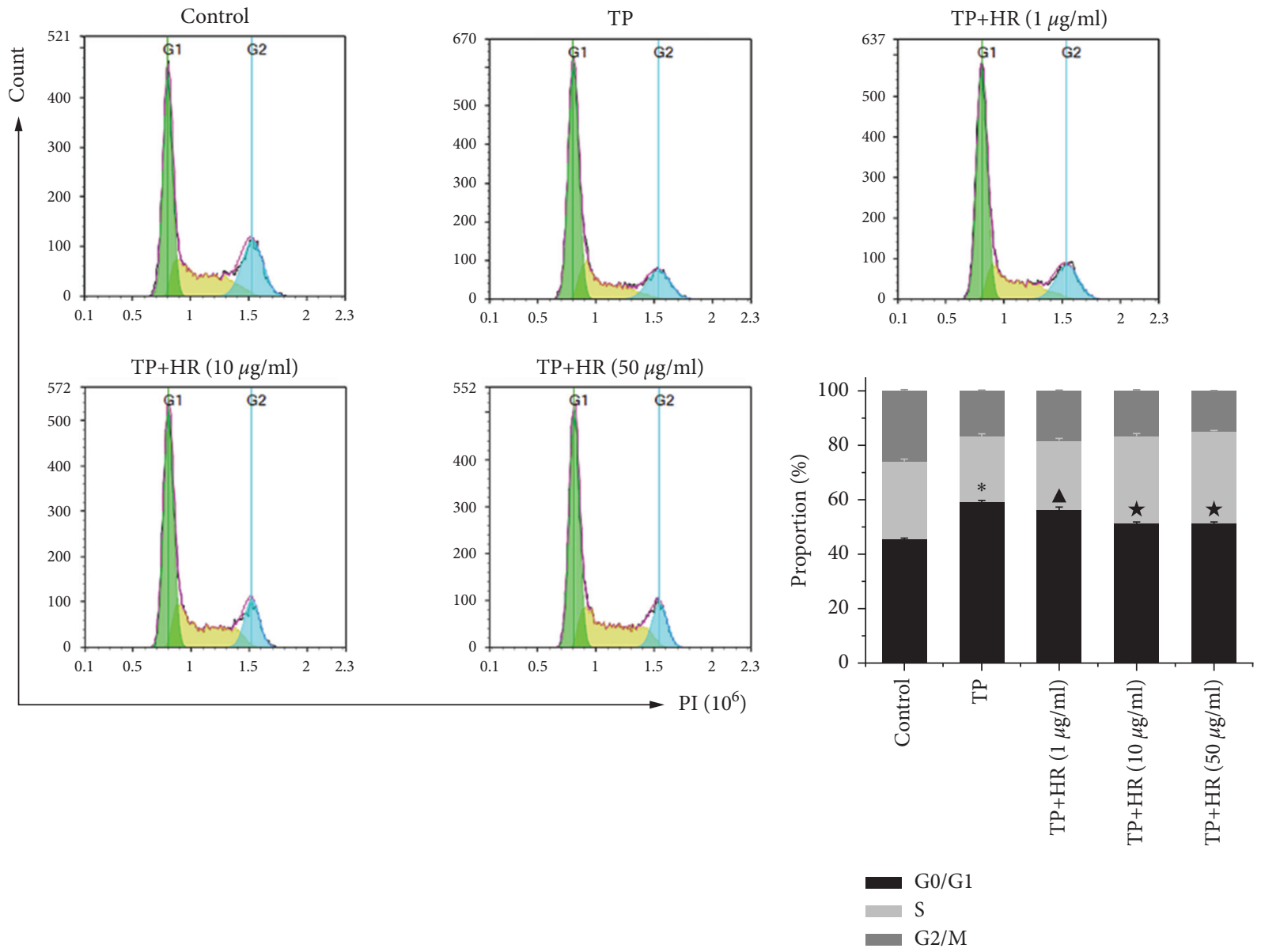

(b)

FIgURE 6: Flow cytometry was performed to detect the (a) apoptosis and (b) cycle of KGN cells treated with TP and HR combination. Data represent as mean \pm standard deviation (SD), $n=3$. $^{*} p<0.05$ vs. control group, ${ }^{\star} p<0.05 \mathrm{vs}$. TP group, and ${ }^{\star} p<0.05 \mathrm{vs}$. TP $+\mathrm{HR}(1 \mu \mathrm{g} / \mathrm{ml})$ group. HR, hyperin; TP, triptolide.

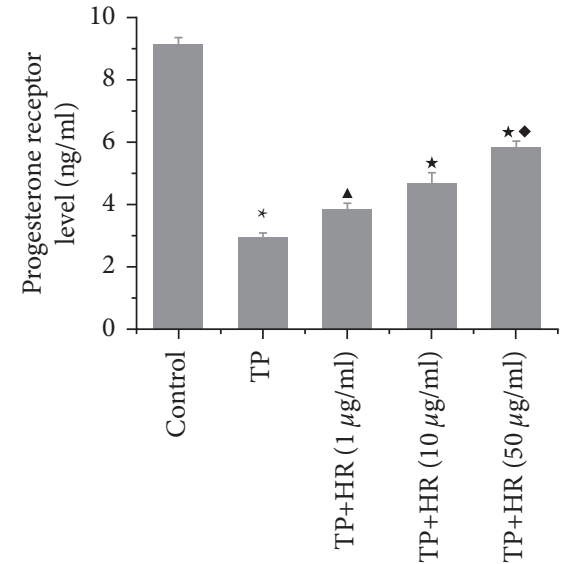

(a)

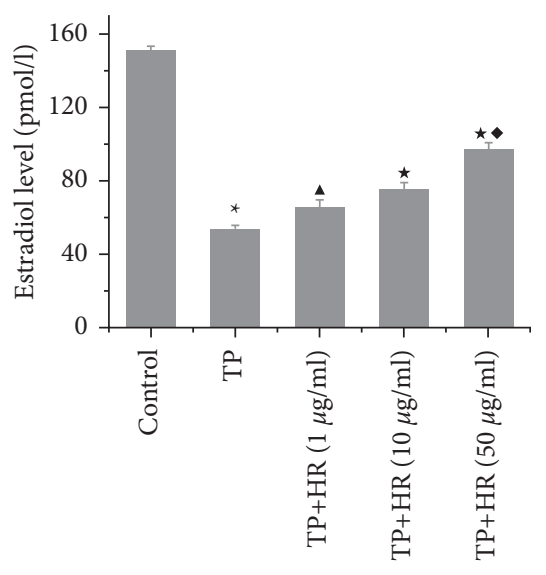

(b)

FIGURE 7: Enzyme-linked immunosorbent assay was performed to evaluate the (a) progesterone receptor and (b) estradiol levels in KGN cells treated with TP and HR combination. Data represent as mean \pm standard deviation (SD), $n=3 .{ }^{*} p<0.05$ vs. control group, ${ }^{\wedge} p<0.05 v s$. TP group, ${ }^{\star} p<0.05 v s$. TP $+\mathrm{HR}(1 \mu \mathrm{g} / \mathrm{ml})$ group, and ${ }^{\star} p<0.05 v s . \mathrm{TP}+\mathrm{HR}(10 \mu \mathrm{g} / \mathrm{ml})$ group. HR, hyperin; TP, triptolide. 

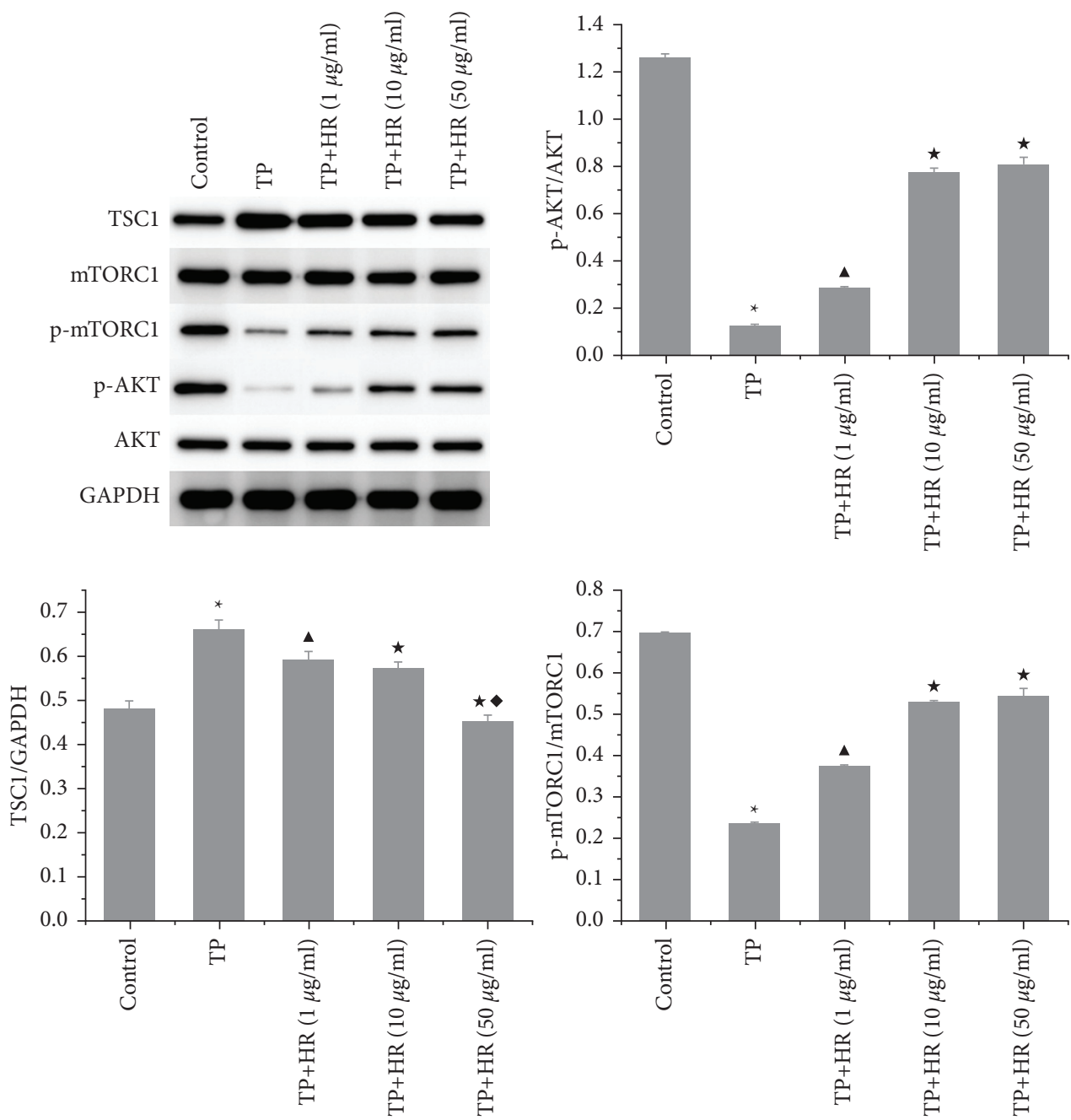

Figure 8: Western blot was performed to detect the expression of TSC1, mTORC1, p-mTORC1, AKT, and p-AKT in KGN cells treated with $\mathrm{TP}$ and HR combination. Data represent as mean \pm standard deviation (SD), $n=3$. $^{*} p<0.05$ vs. control group, ${ }^{\boldsymbol{\Lambda}} p<0.05 v s$. TP group, ${ }^{\star} p<0.05$ vs. TP $+\mathrm{HR}(1 \mu \mathrm{g} / \mathrm{ml})$ group, and ${ }^{\star} p<0.05 v s$. TP + HR $(10 \mu \mathrm{g} / \mathrm{ml})$ group. HR, hyperin; TP, triptolide.

expression of TSC1 in KGN cells. This phenomenon was reversed following HR treatment (Figure 8).

\section{Discussion}

POI refers to early menstruation to stop, and anovulation and decreased estrogen levels according to previous research have shown that its pathogenesis has strong genetic background and high heterogeneity; the genetic factors were involved in the $\mathrm{X}$ chromosome abnormalities, gene mutation, mitochondrial dysfunction, etc., and chromosome abnormality is one of the main causes of POI [34] and has become an important factor of the female infertility. Ovarian failure can cause the follicle to fail to develop, resulting in no ovulation. Granulosa cells (GCs) are associated with oocytes during the development and ovulation of follicles, helping to complete physiological processes such as sperm viability and prokaryotic formation. As the main somatic cells in follicles, ovarian granulosa cells play an important role in follicle growth and development, atresia, oocyte maturation, and ovulation $[27,35]$. The regulation mechanism of hormone synthesis and apoptosis of ovarian granulosa cells is complex and affected by many factors. Hormone synthesis and apoptosis of ovarian granulosa cells are closely related to the regulation of ovarian function.

Principal component analysis revealed that HR was the main active ingredient present in $C$. sinica. HR is a flavonoid compound [36], also known as quercetin-3-O-beta-D-galactoside [37], and it can improve the endocrine function of the ovary [38]. A previous study has reported that HR promotes the proliferation and secretion of estrogen and progesterone in rat ovarian granulosa cells, thereby improving ovarian endocrine function [39]. However, the underlying molecular mechanisms need to be comprehensively elucidated. HR reportedly exhibits several pharmacological activities mediated via different mechanisms. Chao et al. have shown that HR affords a protective effect against cisplatin-induced acute kidney injury by inactivating nuclear factor kappa B and activating nuclear factor E2-related factor-2 signaling [36]. Cao et al. have reported that HR suppresses epilepsy-induced neuronal damage by inhibiting PI3K/AKT and MAPK pathway-mediated oxidative stress and autophagy [40]. Fu et al. 
have demonstrated the anticancer actions of HR in non-small cell lung cancer by inducing apoptosis and autophagy via inhibition of the AKT/mTOR/p70S6K signaling pathway [41]. Zeng et al. have shown that HR protects against amyloid $\beta$ protein-induced neurotoxicity by regulating the PI3K/AKTmediated mitochondrial apoptotic pathway [42]. TSC1 is a crucial upstream negative regulator of $\mathrm{mTORC} 1$. TSC1/2 plays an essential role in the homeostasis and differentiation of immune cells through the negative regulation of the mTOR signaling pathway $[30,31]$. In addition, a previous study has reported that TSC1 is involved in folliculogenesis by adjusting apoptosis and proliferation of granulosa cells [43].

Based on previous studies on PI3K/PTEN/AKT and TSC/ mTORC1 signaling pathways, in the present study, our findings indicated the topological importance of AKT1 in interaction targets of POI and HR through analysis of the proteinPPI network. KEGG pathway analysis showed that HR might regulate POI by modulating the $\mathrm{mTOR}$ signaling pathway. In addition, the KEGG graph for the mTOR signaling [27] pathway revealed that AKT phosphorylation inhibits the activation of TSC1/2, and, in turn, TSC1/2 activation inhibits mTORC1 expression. The in vitro experiment revealed the protective effect of HR against TP-induced injury in KGN cells. The levels of progesterone and estrogen increased, and the antiapoptotic effect of progesterone in ovarian cells was restored. Estrogen and progesterone are necessary in the reproductive process, and their production is closely related. Estrogen is mainly produced in granulosa cells during follicular development and produces negative feedback on luteinizing hormone [44]. Progesterone is synthesized and secreted by follicles and corpus luteum components of mammalian ovary, which can affect the function of granulosa cells during follicular development before ovulation [39]. TSC1 is an important upstream negative regulator of mTORC1. TSC1/2 plays an important role in the homeostasis and differentiation of immune cells by negatively regulating mTOR signaling pathway $[30,31]$. TSC1 participates in folliculogenesis by regulating granulosa cell apoptosis and proliferation. Furthermore, HR increased the phosphorylation of AKT and mTORC1 and decreased TSC1 expression in TP-induced KGN cells, consistent with the KEGG pathway analysis.

Therefore, this study predicted and verified that $\mathrm{HR}$ is involved in regulating the AKT/TSC1/mTORC1 signaling pathway in TP-injured KGN cells. Several studies have revealed the regulatory actions of PI3K/AKT and TSC/mTOR signaling pathways in ovarian function, including differentiation and proliferation of granulosa cells, activation and survival of primordial follicles, and meiotic maturation of oocytes [41]. It is necessary to promote the recovery of granulosa cell activity during POI process and contribute to follicle development, which is extremely necessary for clinical treatment of ovarian insufficiency.

\section{Conclusion}

In conclusion, our findings provide evidence that $\mathrm{HR}$ alleviates TP-induced granulosa cell injury by regulating AKT/ TSC1/mTORC1 signaling. The limitation of this work is that the involvement of the AKT/TSC1/mTORC1 pathway was not confirmed by modulating its activity through transfection or other methods. Collectively, this work further discussed the promotion and mechanism of $C$. sinica compound active ingredient $\mathrm{HR}$ on the proliferation and secretion of damaged granulosa cells, so as to provide a theoretical and experimental basis for the clinical treatment of POI with C. sinica compound and its active ingredients.

\section{Data Availability}

The data used to support the findings of this study are included within the article.

\section{Conflicts of Interest}

All authors declare that they have no conflicts of interest.

\section{Acknowledgments}

Guizhou Science and Technology Fund (No. [2017]5735-02).

\section{Supplementary Materials}

Supplementary 1: the predicted target proteins of HR. Supplementary 2: the predicted targets of POI. Supplementary 3: the interaction targets of HR and POI. Supplementary 4: the degree value, betweenness centrality, and closeness centrality of the interaction targets of HR and POI analyzed using PPI. Supplementary 5: the details of predicted KEGG pathways of interaction targets of HR and POI. (Supplementary Materials)

\section{References}

[1] S. Tsiligiannis, N. Panay, and J. C. Stevenson, "Premature ovarian insufficiency and long-term health consequences," Current Vascular Pharmacology, vol. 17, no. 6, pp. 604-609, 2019.

[2] European Society for Human Reproduction and Embryology (ESHRE) Guideline Group on POI, L. Webber, M. Davies et al., "ESHRE guideline: management of women with premature ovarian insufficiency," Human Reproduction, vol. 31, no. 5, pp. 926-937, 2016.

[3] M. Ghahremani-Nasab, E. Ghanbari, Y. Jahanbani, A. Mehdizadeh, and M. Yousefi, "Premature ovarian failure and tissue engineering," Journal of Cellular Physiology, vol. 235 , no. 5, pp. 4217-4226, 2020.

[4] P. Feng, Q. Xie, Z. Liu, Z. Guo, R. Tang, and Q. Yu, "Study on the reparative effect of $P E G y l a t e d$ growth hormone on ovarian parameters and mitochondrial function of oocytes from rats with premature ovarian insufficiency," Frontiers in Cell and Developmental Biology, vol. 9, Article ID 649005, 2021.

[5] L. Webber, R. A. Anderson, M. Davies, F. Janse, and N. Vermeulen, "HRT for women with premature ovarian insufficiency: a comprehensive review," Human Reproduction Open, vol. 2017, no. 2, Article ID hox007, 2017.

[6] V. Martínez, A. Iriondo De-Hond, F. Borrelli, R. Capasso, M. Dolores del Castillo, and R. Abalo, "Cannabidiol and other non-psychoactive cannabinoids for prevention and treatment of gastrointestinal disorders: useful nutraceuticals?" International Journal of Molecular Sciences, vol. 21, no. 9, 2020. 
[7] G. Vieira, J. Cavalli, E. C. D. Gonçalves et al., “Antidepressantlike effect of terpineol in an inflammatory model of depression: involvement of the cannabinoid system and D2 dopamine receptor," Biomolecules, vol. 10, no. 5, 2020.

[8] S. Hossain, Z. Urbi, H. Karuniawati et al., "Andrographis paniculata (burm. f.) wall. ex nees: an updated review of phytochemistry, antimicrobial pharmacology, and clinical safety and efficacy," Life, vol. 11, no. 4, p. 348, 2021.

[9] M. M. Rahman, A. S. M. Ali Reza, A. K. Muhammed et al., "Unfolding the apoptotic mechanism of antioxidant enriched-leaves of tabebuia pallida in EAC cells," Journal of Ethnopharmacology, vol. 278, Article ID 114297, 2021.

[10] N. M. Abogresha, S. S. Mohammed, M. M. Hosny, H. Y. Abdallah, A. M. Gadallah, and S. M. Greish, "Diosmin mitigates cyclophosphamide induced premature ovarian insufficiency in rat model," International Journal of Molecular Sciences, vol. 22, no. 6, 2021.

[11] E. K. Akkol, "Natural compounds as medical strategies in the prevention and treatment of psychiatric disorders seen in neurological diseases," Frontiers in Pharmacology, vol. 12, 2021.

[12] H. F. Li, Q. H. Shen, W. J. Chen, W. M. Chen, Z. F. Feng, and L. Y. Yu, "Efficacy of traditional Chinese medicine tonifying kidney (bushen) and activating blood (huoxue) prescription for premature ovarian insufficiency: a systematic review and meta-analysis," Evidence-Based Complementary and Alternative Medicine, vol. 2020, Article ID 1789304, 13 pages, 2020.

[13] M.-H. Ping, "Hyperin controls the development and therapy of gastric cancer via regulating wnt/ $\beta$-catenin signaling," Cancer Management and Research, vol. 12, pp. 11773-11782, 2020.

[14] G. Y. Xue, "Clinical observation of Miao medicine Caragana sinica compound in the treatment of decreased ovarian reserve function of kidney yin deficiency type," Cardiovascular Disease Electronic Journal of Integrated Traditional Chinese and Western Medicine, vol. 7, no. 9, pp. 156-157, 2019.

[15] D. Tiosano, F. Paris, M. Grimaldi et al., "Evidence of ERalpha and ERbeta selectivity and partial estrogen agonism in traditional Chinese medicine," Reproductive Biology and Endocrinology: Revista Brasileira de Entomologia, vol. 12, p. 97, 2014.

[16] S. Imamura, M. Tabuchi, H. Oizumi et al., "Yokukansankachimpihange, a traditional Japanese (kampo) medicine, enhances the adaptation to circadian rhythm disruption by increasing endogenous melatonin levels," Journal of Pharmacological Sciences, vol. 144, no. 3, pp. 129-138, 2020.

[17] A. Szeliga, "Autoimmune diseases in patients with premature ovarian insufficiency-our current state of knowledge," International Journal of Molecular Sciences, vol. 22, no. 5, 2021.

[18] L. Boucret, J. M. C. de la Barca, C. Morinière et al., "Relationship between diminished ovarian reserve and mitochondrial biogenesis in cumulus cells," Human Reproduction, vol. 30, no. 7, p. 1653, Article ID 1664, 2015.

[19] L. R. Nelson and S. E. Bulun, "Estrogen production and action," Journal of the American Academy of Dermatology, vol. 45, no. 3supp-S, pp. S116-S124, 2001.

[20] Y. Munakata, R. Kawahara-miki, S. Shiratsuki et al., "Gene expression patterns in granulosa cells and oocytes at various stages of follicle development as well as in in vitro grown oocyte-and-granulosa cell complexes," Journal of Reproduction and Development, vol. 62, no. 4, pp. 359-366, 2016.

[21] M. M. İnal, A. Incebiyik, M. Sanci, Y. Yildirim, and M. Polat, "Ovarian cysts in tamoxifen-treated women with breast cancer," European Journal of Obstetrics \& Gynecology and Reproductive Biology, vol. 120, no. 1, pp. 104-106, 2005.

[22] S. Cecconi, C. Ciccarelli, M. Barberi, G. Macchiarelli, and R. Canipari, "Granulosa cell-oocyte interactions," European Journal of Obstetrics \& Gynecology and Reproductive Biology, vol. 115, pp. S19-S22, 2004.

[23] J. L. V. Shaw, S. K. Dey, H. O. D. Critchley, and A. W. Horne, "Current knowledge of the aetiology of human tubal ectopic pregnancy," Human Reproduction Update, vol. 16, no. 4, pp. 432-444, 2010.

[24] E. Asselin, C. W. Xiao, Y. F. Wang, and B. K. Tsang, "Mammalian follicular development and atresia: role of apoptosis," Neurosignals, vol. 9, no. 2, pp. 87-95, 2000.

[25] J. L. Tilly, K. I. Kowalski, A. L. Johnson, and A. J. W. Hsueh, "Involvement of apoptosis in ovarian follicular atresia and postovulatory regression," Endocrinology, vol. 129, no. 5, pp. 2799-2801, 1991.

[26] F. Yang, Y. Chen, Q. Liu, S. Dai, and S. Zeng, "Dynamics and regulations of BimEL Ser65 and Thr112 phosphorylation in porcine granulosa cells during follicular atresia," Cells, vol. 9, no. 2, 2020.

[27] F. Matsuda, N. Inoue, N. Manabe, and S. Ohkura, "Follicular growth and atresia in mammalian ovaries: regulation by survival and death of granulosa cells," Journal of Reproduction and Development, vol. 58, no. 1, pp. 44-50, 2012.

[28] A. Deepak, W. Zheng, Y. Shen et al., "Tsc/mTORC1 signaling in oocytes governs the quiescence and activation of primordial follicles," Human Molecular Genetics, vol. 19, no. 3, pp. 397-410, 2010.

[29] A. Makker, M. M. Goel, and A. A. Mahdi, "PI3K/PTEN/Akt and TSC/mTOR signaling pathways, ovarian dysfunction, and infertility: an update," Journal of Molecular Endocrinology, vol. 53, no. 3, pp. R103-R118, 2014.

[30] Y. Hui, X. Wang, Y. Zhang et al., "Modulation of TSC-mTOR signaling on immune cells in immunity and autoimmunity," Journal of Cellular Physiology, vol. 229, no. 1, pp. 17-26, 2014.

[31] K. Inoki, M. N. Corradetti, and K. L. Guan, "Dysregulation of the TSC-mTOR pathway in human disease," Nature Genetics, vol. 37, no. 1, pp. 19-24, 2005.

[32] X.-Y. Chen, W.-L. Chen, M. Ma, C. Gu, X.-R. Xiao, and B. Li, "The potential of follicle-stimulating hormone peptidemodified triptolide-loaded nanoparticles to induce a mouse model of premature ovarian insufficiency," International Journal of Nanomedicine, vol. 10, pp. 2765-2774, 2015.

[33] C. Xi, S. Peng, Z. Wu, Q. Zhou, and J. Zhou, "Toxicity of triptolide and the molecular mechanisms involved," Biomedecine \& Pharmacotherapie, vol. 90, pp. 531-541, 2017.

[34] M. D. Vos, P. Devroey, and B. C. J. M. Fauser, "Primary ovarian insufficiency," The Lancet, vol. 376, no. 9744, pp. 911-921, 2010.

[35] M. Tiwari, S. Prasad, A. Tripathi et al., "Apoptosis in mammalian oocytes: a review," Apoptosis, vol. 20, no. 8, pp. 1019-1025, 2015.

[36] C.-S. Chao, C.-S. Tsai, Y.-P. Chang, J.-M. Chen, H.-K. Chin, and S.-C. Yang, "Hyperin inhibits nuclear factor kappa B and activates nuclear factor E2-related factor-2 signaling pathways in cisplatin-induced acute kidney injury in mice," International Immunopharmacology, vol. 40, pp. 517-523, 2016.

[37] S. Karakaya, I. Süntar, O. F. Yakinci et al., "In vivo bioactivity assessment on Epilobium species: a particular focus on Epilobium angustifolium and its components on enzymes connected with the healing process," Journal of Ethnopharmacology, vol. 262, Article ID 113207, 2020. 
[38] J. Wang, M. Wang, Y. Ou, and Q. Wu, "Effects of flavonoids from semen Cuscutae on changes of beta-EP in hypothalamuses and FSH and $\mathrm{LH}$ in anterior pituitaries in female rats exposed to psychologic stress," Journal of Chinese Medicinal Materials, vol. 25, no. 12, pp. 886-888, 2002.

[39] X. Nie, W. Sheng, D. Hou, Q. Liu, R. Wang, and Y. Tan, "Effect of Hyperin and Icariin on steroid hormone secretion in rat ovarian granulosa cells," Clinica Chimica Acta, vol. 495, pp. 646-651, 2019.

[40] J. Cao, C. Tang, M. Gao et al., "Hyperoside alleviates epilepsyinduced neuronal damage by enhancing antioxidant levels and reducing autophagy," Journal of Ethnopharmacology, vol. 257, Article ID 112884, 2020.

[41] T. Fu, L. Wang, X.-n. Jin, H.-j. Sui, Z. Liu, and Y. Jin, "Hyperoside induces both autophagy and apoptosis in nonsmall cell lung cancer cells in vitro," Acta Pharmacologica Sinica, vol. 37, no. 4, pp. 505-518, 2016.

[42] K. W. Zeng, X.-M. Wang, H. Ko, H. C. Kwon, J. W. Cha, and H. O. Yang, "Hyperoside protects primary rat cortical neurons from neurotoxicity induced by amyloid beta-protein via the PI3K/Akt/Bad/Bcl(XL)-regulated mitochondrial apoptotic pathway," European Journal of Pharmacology, vol. 672, no. 1-3, pp. 45-55, 2011.

[43] X. Yuan, X. Deng, X. Zhou et al., "MiR-126-3p promotes the cell proliferation and inhibits the cell apoptosis by targeting TSC1 in the porcine granulosa cells," in In Vitro Cellular \& Developmental Biology: Animal, vol. 54, pp. 715-724, , no. 10, Tissue Culture Association, Manassas, VA, USA, 2018.

[44] J. K. Findlay, K. Britt, J. B. Kerr et al., "The road to ovulation: the role of oestrogens," Reproduction, Fertility, and Development, vol. 13, no. 7-8, pp. 543-547, 2001. 